\title{
Younger age and female gender are determinants of underestimated cardiovascular risk in rheumatoid arthritis patients: a prospective cohort study
}

Daphne C. Rohrich ${ }^{1}$ (D) Eline H. M. van de Wetering ${ }^{2}$, Alexander J. Rennings ${ }^{3}$, Elke E. Arts $^{2}$ (D) Inger L. Meek ${ }^{2}$, Alfons A. den Broeder ${ }^{1}$ (D) Jaap Fransen ${ }^{2}$ and Calin D. Popa ${ }^{1,2^{*}}$ (D)

\begin{abstract}
Background: Rheumatoid arthritis (RA) patients have an increased cardiovascular (CV) risk. Here, we aimed to investigate whether gender and age are contributing to the misclassification of CV risk in RA patients.

Methods: Prospectively collected data on cardiovascular risk factors and incident events from the Nijmegen inception cohort were analyzed, with up to 10 years follow-up. Original as well as the EULAR-modified (M)_SCORE algorithms were used to calculate CV risk. Patients were stratified in deciles according to predicted risk; the HosmerLemeshow test was used to check concordance between observed and predicted risk, in subgroups of gender and age.

Results: There were 863 RA patients included with 128 incident CV events. When using SCORE in the whole group, there was evidence of a discrepancy between the predicted and observed $\mathrm{CV}$ risk ( $\mathrm{H}-\mathrm{L}$ test $p<0.003)$, mainly present in the female subgroup ( $\mathrm{H}-\mathrm{L}$ test $p<0.001$ ). Interestingly, $36 \%$ of females who developed an event belonged to the low CV risk group, whereas this was just 10\% in RA males. When analyzing the subgroups based on age, a discrepancy was present only in the youngest patients ( $H$-L test $p<0.001$ in patients $<55$ years) consisting of an underestimation of CV risk (5.3\% predicted vs. 8.0\% observed). Similar results were obtained when the M_SCORE was applied.

Conclusion: CV risk is especially underestimated in female and younger RA patients. This suggests that modifying the weight for the female gender and/or younger age in currently used CV risk algorithms might improve their predictive value in RA, contributing to better CV risk management.
\end{abstract}

Keywords: Rheumatoid arthritis, Cardiovascular, Risk factors, Age, Gender

\footnotetext{
*Correspondence: c.popa@maartenskliniek.nl

'Department of Rheumatology, Sint Maartenskliniek, Hengstdal nr. 3, 6574

NA Ubbergen, The Netherlands

2Department of Rheumatology, Radboud University Nijmegen Medical

Centre, Geert Grooteplein 8, 6500 HB Nijmegen, The Netherlands

Full list of author information is available at the end of the article
}

C C The Author(s). 2021 Open Access This article is licensed under a Creative Commons Attribution 4.0 International License, which permits use, sharing, adaptation, distribution and reproduction in any medium or format, as long as you give appropriate credit to the original author(s) and the source, provide a link to the Creative Commons licence, and indicate if changes were made. The images or other third party material in this article are included in the article's Creative Commons licence, unless indicated otherwise in a credit line to the material. If material is not included in the article's Creative Commons licence and your intended use is not permitted by statutory regulation or exceeds the permitted use, you will need to obtain permission directly from the copyright holder. To view a copy of this licence, visit http://creativecommons.org/licenses/by/4.0/ The Creative Commons Public Domain Dedication waiver (http://creativecommons.org/publicdomain/zero/1.0/) applies to the data made available in this article, unless otherwise stated in a credit line to the data. 


\section{Introduction}

Rheumatoid arthritis (RA) patients have a higher risk of developing cardiovascular diseases (CVD) than the general population [1]. It has been previously suggested that this increased risk of CVD is in part due to systemic inflammation seen in patients with RA, although excess in classical risk factors like smoking and obesity also play a role [2].

Current algorithms developed to predict CVD, such as the Systematic Coronary Risk Evaluation score (SCORE), underestimate the risk in RA patients, especially in those patients originally classified as having low or intermediate risk [3]. It is well known that older age leads to higher $\mathrm{CV}$ risk in the general population. Likewise, males are at greater risk compared to females. However, the results of a recent meta-analysis suggested that compared to the general population, younger RA patients bear the greatest relative risk of developing CV events, whereas older RA patients seem to have similar relative risks when compared to age-matched counterparts [4]. Furthermore, women with RA seem to be at a greater $\mathrm{CV}$ risk than those without RA [5]. Early menopause seems to be a predictor for RA, and in addition, early menopause in women with RA may lead to a higher CVD risk [6-8]. Therefore, one can suggest that gender and age are likely to have a distinct impact on CVD risk in RA patients than in the general population.

Because the majority of risk calculators such as the SCORE risk charts use standard weighing of gender and age, their unadjusted use to patients with RA would yield inappropriate estimates of the $\mathrm{CV}$ risk. Because this hypothesis has been generated from results coming from a meta-analysis, we aimed in this study to confirm in a prospective follow-up inception cohort of RA patients whether age and gender are contributing to the underestimation, and thus misclassification, of CV risk in RA when current risk algorithms developed for the general population are used. Adjusting the impact of these parameters to better suit the RA population has not been part of the present investigation.

\section{Patients and methods Design}

For this study, prospectively collected data on cardiovascular risk factors and incident events from the Nijmegen early RA inception cohort, with a follow-up of up to 10 years, were used. In the cohort, patients had been included at diagnosis of RA (baseline) in the outpatient clinic of the Department of Rheumatology of the Radboud University Nijmegen Medical Centre (since 1985) or the Maartenskliniek Nijmegen (since 1990). Patients were included when they had a disease duration of $<1$ year, were diseasemodifying antirheumatic drug (DMARD) naive, and fulfilled the 1987 American College of Rheumatology (ACR) criteria (before 2010) or the ACR/EULAR 2010 criteria. All patients provided written informed consent.

For the current analysis, patients with a history of CVD prior to RA diagnosis were excluded. The SCORE and the EULAR-modified SCORE algorithm were used for the prediction of CVD risk [9].

\section{Baseline data}

Baseline characteristics were retrieved from the cohort database, including age (years), gender (male/female), rheumatoid factor (RF) positivity, anti-cyclic citrullinated peptide (aCCP) antibody positivity, and Disease Activity Score (DAS-28) at disease diagnosis. Baseline data regarding CV risk factors were collected by medical chart and electronic patient file review, including smoking status $(\mathrm{Y} /$ $\mathrm{N})$, blood pressure $(\mathrm{mmHg})$, height $(\mathrm{m})$, weight $(\mathrm{kg})$, diabetes mellitus $(\mathrm{Y} / \mathrm{N})$, hypertension $(\mathrm{Y} / \mathrm{N})$, and family history of CVD $(\mathrm{Y} / \mathrm{N})$. Non-fasting total cholesterol and high-density lipoprotein cholesterol concentrations $(\mathrm{mmol} / \mathrm{l})$ were measured according to the standard laboratory procedures. CV events within 10 years were retrieved from physician diagnosis and extensive review of medical charts and electronic patient files. Acute coronary syndrome (myocardial infarction and unstable angina pectoris), stable angina pectoris (sAP), cerebral vascular accident (CVA), transient ischemic attack (TIA), peripheral artery disease (PAD), percutaneous transluminal coronary angioplasty (PTCA), coronary artery bypass grafting (CABG), and coronary angiography (CAG) were included $\mathrm{CV}$ events. Deaths due to CVD were verified from death certificates, provided by the Statistics Netherlands [10], including deaths due to CVD and CVA but excluding cerebral hemorrhage and non-coronary cardiac death.

\section{Statistical analysis}

Baseline data were used to calculate individual risks for $\mathrm{CV}$ events within 10 years for both CV risk algorithms. Missing values were imputed using multiple imputations with five repetitions. Baseline differences between the groups of RA patients with or without a CV event at follow-up were analyzed using the $t$ test or $\chi^{2}$ test, as appropriate. The predicted risks for a $\mathrm{CV}$ event in patients with a follow-up time of $<10$ years were adjusted proportionally, according to the length of actual follow-up, and calculated as a proportion of 10 years. The HosmerLemeshow (H-L) test was used to check the concordance between the observed and predicted risk, in subgroups based on gender and age. All statistical analyses were performed using SPSS V.20.0.

\section{Results}

Patient characteristics

A total of 863 prospectively followed RA patients were included in the analysis, of whom 566 were female and 
Table 1 Patient characteristics in the two groups, with and without incident CV events

\begin{tabular}{llll}
\hline Parameter & CVD- $(\boldsymbol{N}=\mathbf{7 3 5})$ & CVD+ $(\boldsymbol{N}=\mathbf{1 2 8})$ & $\boldsymbol{p}$ value \\
\hline Age (years) & $53.2 \pm 13.6$ & $61.2 \pm 10.2$ & $<0.0001$ \\
Gender, F (\%) & 68 & 52 & $<0.0001$ \\
Smoker (\%) & 30 & 41 & 0.042 \\
TC (mmol/l) & $5.22 \pm 1.23$ & $5.26 \pm 1.34$ & 0.72 \\
HDL (mmol/l) & $1.30 \pm 0.30$ & $1.24 \pm 0.28$ & 0.040 \\
TC:HDL & $4.11 \pm 0.87$ & $4.32 \pm 0.96$ & 0.014 \\
SBP (mmHg) & $146 \pm 23$ & $155 \pm 24$ & $<0.0001$ \\
DBP (mmHg) & $84 \pm 12$ & $86 \pm 9$ & 0.038 \\
DAS-28 & $4.84 \pm 1.26$ & $5.39 \pm 1.33$ & $<0.0001$ \\
RF+ (\%) & 74 & 79 & 0.27 \\
aCCP+ (\%) & 67 & 66 & 0.83
\end{tabular}

Results are expressed as percentages or as means \pm standard deviation (SD) CVD cardiovascular disease, $F$ female, $T C$ total cholesterol, HDL high-density lipoprotein, SBP systolic blood pressure, $D B P$ diastolic blood pressure, DAS-28 Disease Activity Score, $R F$ rheumatoid factor, aCCP anti-cyclic citrullinated peptide
297 were male. During the follow-up, 128 cardiovascular events had been recorded. Expectedly, patients who developed $\mathrm{CV}$ events had more classical CV risk factors at baseline, such as high blood pressure or smoking (Table 1). On average, patients with CVD events were older and were more likely to be male compared to patients without CVD events. The DAS-28 was higher in patients with CVD, but there were no differences in the occurrence of rheumatoid factor (RF) or anti-CCP antibodies between the two groups (Table 1).

\section{Influence of gender on CVD risk prediction}

As shown (Fig. 1a), in the group of females with RA, most patients had a low predicted CV risk (59\%), whereas in RA males, $68 \%$ had an intermediary or high (46\%) CV risk. In the total group, there was a discrepancy between predicted and observed $\mathrm{CV}$ risk ( $\mathrm{H}-\mathrm{L}$ test $p<0.003)$ when the SCORE algorithm was applied. When analyzed separately for females and males (Fig. 1b), this discrepancy appeared to be especially present in the female subgroup ( $\mathrm{H}-\mathrm{L}$ test $p<0.001)$,
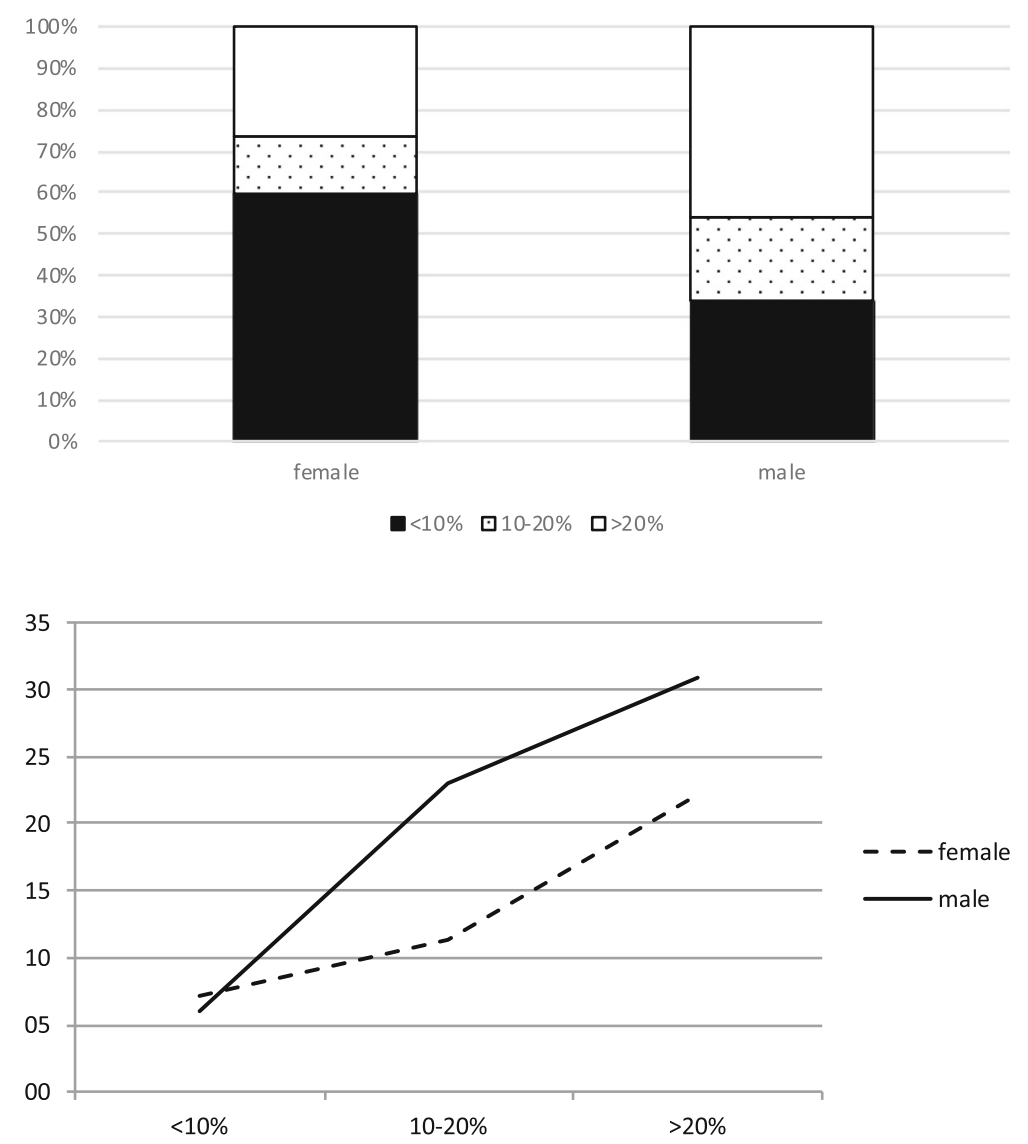

Fig. 1 The distribution of CV risk. a The distribution of CV risk among women and men with RA: low CV risk (white bar), intermediary CV risk (gray bar), and high CV risk (black bar). b The observed percentages (Y-axis) of female (dotted line) and male (black line) RA patients who experienced a new CV event during the follow-up period, according to their predicted CV risk category ( $X$-axis): low ( $<10 \%)$, intermediary $(10-20 \%)$, and high (> 20\%) 
Table 2 Observed CV event distribution in the studied group, according to gender and CV risk group

\begin{tabular}{|c|c|c|c|c|c|c|c|c|c|}
\hline \multirow{2}{*}{$\begin{array}{l}\text { CV risk } \\
\text { calculator }\end{array}$} & \multicolumn{3}{|c|}{$<10 \%$} & \multicolumn{3}{|c|}{$10-20 \%$} & \multicolumn{3}{|c|}{$>20 \%$} \\
\hline & $N$ & CVD+ & $\%(A R)$ & $N$ & CVD+ & $\%(A R)$ & $N$ & CVD+ & $\%(A R)$ \\
\hline \multicolumn{10}{|c|}{ SCORE } \\
\hline $\mathrm{F}$ & 336 & 24 & 7.1 & 80 & 9 & 11.3 & 149 & 33 & 22.1 \\
\hline M & 100 & 6 & 6.0 & 61 & 14 & 23.0 & 136 & 42 & 30.9 \\
\hline T & 436 & 30 & 6.9 & 141 & 23 & 16.3 & 285 & 75 & 26.3 \\
\hline \multicolumn{10}{|l|}{ FRS } \\
\hline $\mathrm{F}$ & 271 & 13 & 4.8 & 168 & 23 & 13.7 & 127 & 30 & 23.6 \\
\hline M & 65 & 2 & 3.1 & 77 & 14 & 18.2 & 155 & 47 & 30.3 \\
\hline $\mathrm{T}$ & 336 & 15 & 4.5 & 245 & 37 & 15.1 & 282 & 77 & 27.3 \\
\hline \multicolumn{10}{|c|}{ QR2 } \\
\hline $\mathrm{F}$ & 262 & 14 & 5.3 & 129 & 17 & 13.2 & 175 & 35 & 20.0 \\
\hline M & 68 & 4 & 5.9 & 69 & 9 & 13.0 & 160 & 50 & 31.1 \\
\hline T & 330 & 18 & 5.5 & 198 & 26 & 13.1 & 335 & 85 & 25.4 \\
\hline
\end{tabular}

CV cardiovascular, CVD cardiovascular disease, AR absolute risk, FRS Framingham Risk Score, QR2 QRisk2, $F$ females, $M$ males, $T$ total

rather than in the male subgroup ( $\mathrm{H}-\mathrm{L}$ test $p=0.09)$. Interestingly, in the group of RA patients having a low predicted CV risk $(<10 \%)$, the proportion of females still experiencing an incident $\mathrm{CV}$ event at follow-up is higher than that of the males and higher than predicted as well (Table 2). This was not the case in the other two risk groups (intermediary and high $\mathrm{CV}$ risk group), where males had a CV event more often (Table 2).

When looking at the distribution of RA patients who experienced a CV event by gender and their initially assigned CV risk group (Fig. 2), it appeared that among the group of females who developed CVD, 36\% had a predicted risk lower than $10 \%$ (low predicted risk). In comparison, only $10 \%$ of males who developed CVD had a predicted risk lower than $10 \%$ (Fig. 2). Overall, the majority of RA patients who developed CVD and have been initially assigned to the lower-risk group were eventually women, whereas RA men were more often seen in the intermediary- and high-risk groups (Fig. 2). Similar results were obtained when the M-SCORE was applied.

\section{Influence of age on CVD risk prediction}

To analyze the influence of age on CVD risk prediction, subgroups were made based on age: $<55$ years, $55-65$ years, and $>65$ years. Almost $30 \%$ of all the CV events had been registered in the youngest RA patients' group ( $<55$ years), whereas the oldest patients ( $>65$ years) accounted for $38 \%$ of all CV events (Table 3). The H-L test values of the three age groups were $p<0.001, p=$

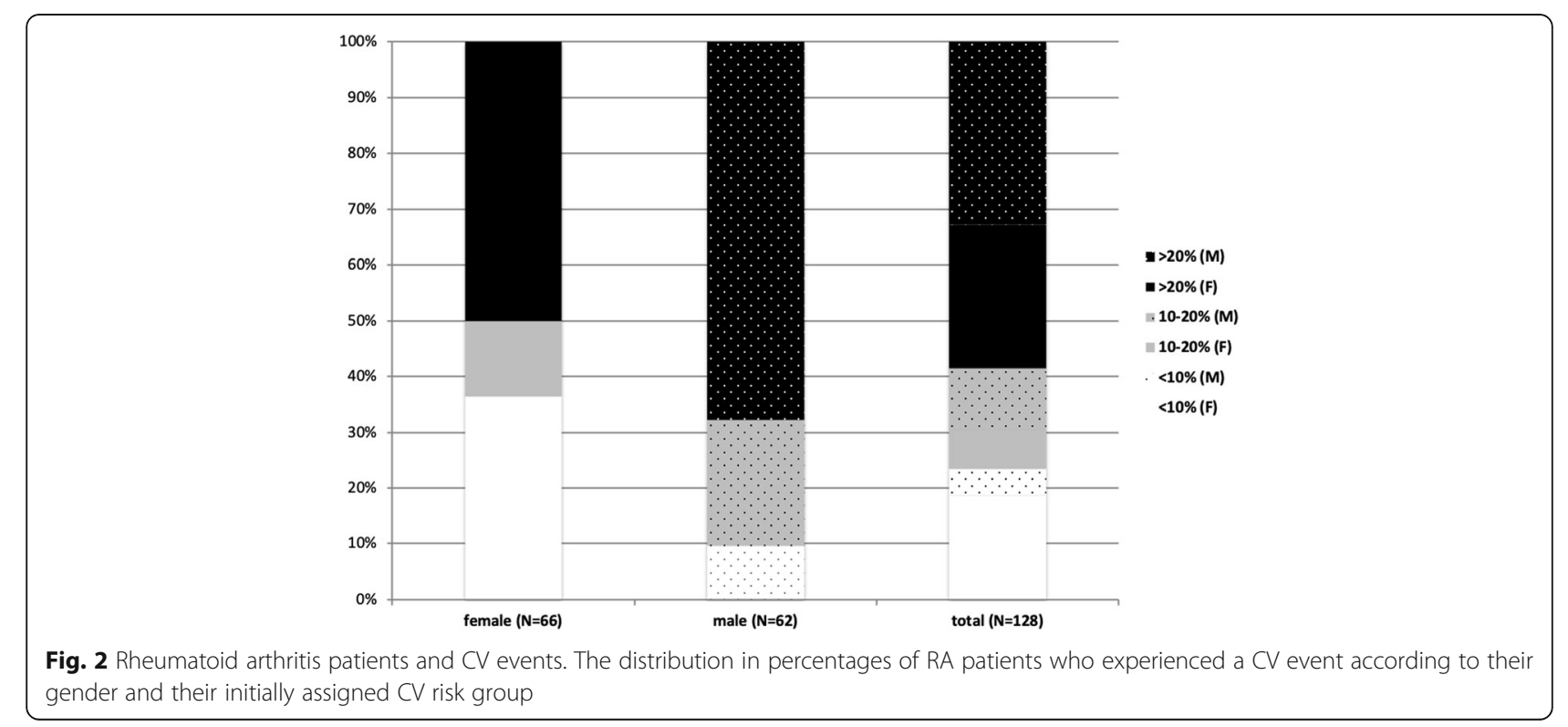


Table 3 CV event distribution in the studied group, according to age and CV risk group

\begin{tabular}{|c|c|c|c|c|c|c|c|c|c|c|}
\hline \multirow{2}{*}{$\begin{array}{l}\text { Age } \\
\text { (years) }\end{array}$} & \multicolumn{3}{|c|}{ SCORE risk group $<10 \%$} & \multicolumn{3}{|c|}{ SCORE risk group $10-20 \%$} & \multicolumn{3}{|c|}{ SCORE risk group $>20 \%$} & \multirow{2}{*}{$\begin{array}{l}\text { Total } \\
\text { CVD+ }\end{array}$} \\
\hline & $\bar{N}$ & CVD+ & $\%($ AR) & $\bar{N}$ & CVD+ & $\%(A R)$ & $\bar{N}$ & CVD+ & $\%(A R)$ & \\
\hline$<55$ & 381 & 25 & 7 & 41 & 10 & 24 & 16 & 3 & 19 & 38 \\
\hline $55-65$ & 55 & 5 & 9 & 89 & 13 & 15 & 95 & 23 & 24 & 41 \\
\hline$>65$ & 0 & 0 & - & 11 & 0 & 0 & 174 & 49 & 28 & 49 \\
\hline
\end{tabular}

CVD cardiovascular disease, $A R$ absolute risk

0.93 , and $p=0.96$, respectively (Fig. 3 ), pointing to the misclassification (underestimation) of $\mathrm{CV}$ risk in the youngest RA patients (5.3\% predicted vs. $8.0 \%$ observed). Similar results were obtained when the M-SCORE was applied.

\section{Discussion}

According to the results of this study, younger $(<55) \mathrm{RA}$ patients and females with RA are likely to form two subgroups with the largest underestimation of CVD risk, if $\mathrm{CV}$ risk algorithms developed for the general population (SCORE) were used. The present results confirm those previously obtained in meta-analysis [4]. RA is associated with an increased risk of developing acute CV events. Following EULAR recommendations [9], patients receiving the diagnosis RA should be further monitored for the presence of risk factors for CVD. Risk management should be initiated by firstly determining the 10 -year risk to develop CV events. Various risk calculators have been used so far, yet none of them appears to perform in RA patients as well as in the general population [3]. Attempts to modify these algorithms in order to better fit the RA population, including the addition of inflammatory parameters, disease activity markers, or even genetic markers, have yielded disappointing results [11-13], although one recent algorithm might lead to some improvement in accuracy [14]. The results of the present study yield the hypothesis of modifying the weight of gender and/or age in current CV risk calculators to better fit RA patients. This hypothesis warrants further attention in the future, yet it does not constitute the aim of the present study.

In the current study, RA females accounted for the vast majority of CV events in the low-risk group (80\%), which eventually represented over one third of all CV events in RA women. In comparison, the distribution of

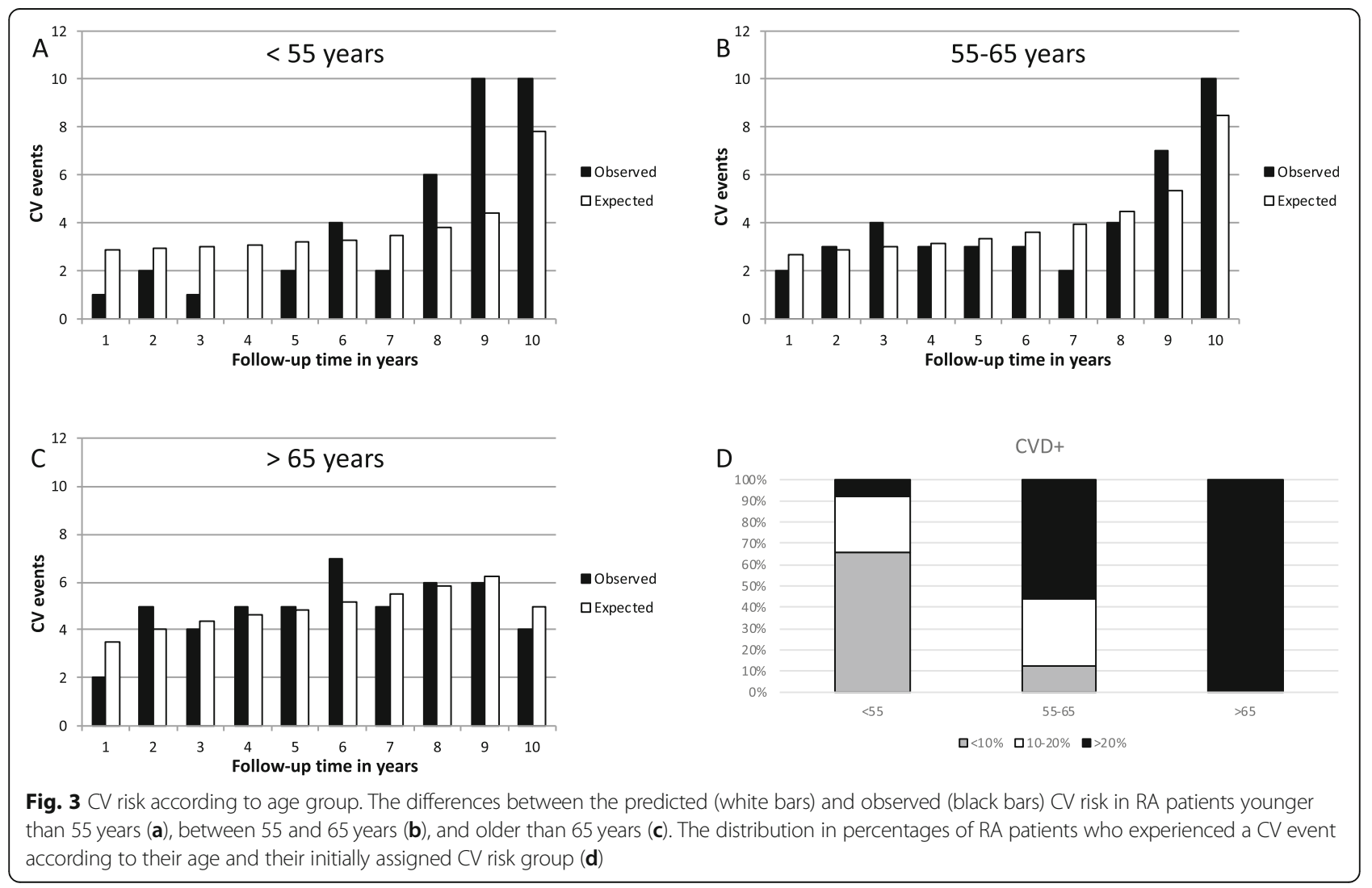


$\mathrm{CV}$ events in RA men was more in accordance with their predicted risk category, being the lowest $(10 \%)$ in the low-risk group and highest (68\%) in RA men initially assigned to the high-risk group. It seems therefore that at diagnosis, CVD risk is especially underestimated in females, and there are indeed several putative explanations for this. Firstly, previous studies have suggested that females and males with RA are not equally affected by inflammation with respect to $\mathrm{CV}$ risk factors. In line with this, we have previously shown that compared to healthy volunteers, the HDL-2 subfraction is declined in females with RA but not in males [5]. Also, it is hypothesized that due to systemic inflammation, females with RA reach menopause earlier than normally expected, which is augmenting their $\mathrm{CV}$ risk as compared to non-RA women of similar age $[6,15]$. Finally, low-grade inflammation and a disturbed metabolism, as it is the case in diabetes mellitus, may augment the $\mathrm{CV}$ risk much more in women (relative risk 3 to 8 times higher) than in men (relative risk 2 to 3 times higher) as compared to the general population [16].

In our study, CV events occurred very often even in young RA patients and accounted eventually for almost $30 \%$ of all the registered CV events. Among them, two thirds have been initially assigned to the group of low $\mathrm{CV}$ risk at baseline. Age is a very strong predictor of future CV risk. According to the SCORE chart in The Netherlands, women under 55 and men under 50 would nearly always have a low CV risk, independent of the other CV risk factors such as dyslipidemia, hypertension, and smoking status. Consequently, according to the epidemiological data, individuals belonging to this risk category should not initiate drug therapies, as these would have a very limited impact on their CV risk, which is low already. Nevertheless, previous studies performed in RA populations have indicated the presence of atherosclerotic plaques even in younger patients and/or patients assigned to the low CV risk category [17, 18]. Accordingly, one third of RA women who had a low SCORE value and are aged $>49.5$ years or/and have a total cholesterol concentration of $>5.4 \mathrm{mmol} / \mathrm{l}$ experience high-risk atherosclerosis and would therefore require intensive CVD risk management [19]. As carotid artery intima-media thickness (cIMT) and coronary artery calcification (CAC) score are both surrogate markers of underlying atherosclerosis and are both associated with increased CV risk, this suggests that these patients bear a higher $\mathrm{CV}$ risk than the one initially assigned using just the SCORE risk calculator. Of note, cIMT is likely to be more sensitive than CAC in RA patients in order to detect subclinical atherosclerosis associated with high CV risk [20]. Our results strengthen this hypothesis from an epidemiological perspective, as the number of the observed $\mathrm{CV}$ events was higher than predicted in the low-CV risk group of patients. These observations might also be explained from a pathophysiological perspective. Atherosclerosis is accelerated in RA patients [21], most probably due to dyslipidemia, which is widely present $[5,22]$, and due to inflammation during periods of active disease, which may contribute to plaque development and instability/rupture [23]. In other words, it seems that RA patients would need less time (thus would be younger) to reach a critical level of vulnerability of atherosclerotic lesions that would trigger an acute event, as compared to the general population, as suggested by the data of the present study and our previous meta-analysis [4]. We are aware of the low absolute risk in the lower CV risk category patients. Nevertheless, we consider that these results cannot be neglected and should lead to a better performance of risk predictions in the "low-risk" group. Because this is the group where most health gain may be achieved, as these patients have the highest chance of being most often undertreated for their traditional CV risk factors and therefore more prone to develop CVD.

Our study has a few limitations. Firstly, the number of patients included is limited as compared with studies of CVD in the general population. Yet, the cohort used is well and prospectively documented, and also one of the largest single-center cohorts of its kind. Secondly, most of the patients investigated were included before CVD risk management had been implemented, limiting the use of absolute risk predictions. Thirdly, our study investigated if current algorithms have a proper calibration in the subgroups tested (i.e., gender and age-specific subgroups). No statistical comparisons of calibrations between the groups have been made. Finally, data on the use of non-steroidal anti-inflammatory drugs (NSAIDs) and corticosteroids are missing. This might have influenced the results of the study, though some recent reports suggest that the use of NSAIDs does not increase $\mathrm{CV}$ incidence in the RA population as compared to osteoarthritis (OA) [24].

\section{Conclusions}

In conclusion, the results of our study suggest that the incidence of CVD among women and young RA patients initially assigned to the low-risk category is higher than predicted using current algorithms. Consequently, the $\mathrm{CV}$ risk in these subgroups seems underestimated. Whether modifying the weight for the female gender and/or younger age in the risk algorithms would result in better CV risk predictions in RA remains a subject to be investigated in future studies. Alternatively, other strategies (e.g., biomarkers, cIMT, or CAC measurements) aiming at the same goal could be envisaged in order to improve $\mathrm{CV}$ risk management in patients with RA and/or other chronic inflammatory conditions. 


\section{Abbreviations}

RA: Rheumatoid arthritis; CV: Cardiovascular; EULAR: European League Against Rheumatism; H-L test: Hosmer-Lemeshow test; CVD: Cardiovascular diseases; SCORE score: Systematic Coronary Risk Evaluation score; DMAR D: Disease-modifying antirheumatic drug; ACR: American College of Rheumatology; RF: Rheumatoid factor; aCCP: Anti-cyclic citrullinated peptide; DAS-28: Disease Activity Score; sAP: Stable angina pectoris; CVA: Cerebral vascular accident; TIA: Transient ischemic attack; PAD: Peripheral artery disease; PTCA: Percutaneous transluminal coronary angioplasty; CABG: Coronary artery bypass grafting; CAG: Coronary angiography; TC: Total cholesterol; HDL: High-density lipoprotein; SBP: Systolic blood pressure; DBP: Diastolic blood pressure; CIMT: Carotid artery intima-media thickness; CAC: Coronary artery calcification; NSAIDs: Non-steroidal anti-inflammatory drugs; OA: Osteoarthritis

\section{Acknowledgements}

Not applicable

\section{Authors' contributions}

$\mathrm{CP}$ and JF are responsible for the design and development of these analyses. $\mathrm{DR}, \mathrm{EVW}$, and EA are responsible for the acquisition of the data. DR, EvW, and $\mathrm{CP}$ analyzed or interpreted the data. All authors critically revised the manuscript and are accountable for the accuracy and integrity. The authors read and approved the final manuscript.

\section{Funding}

Not applicable.

\section{Availability of data and materials}

The datasets used and/or analyzed during the current study are available from the corresponding author on reasonable request.

\section{Ethics approval and consent to participate}

Conform to the Declaration of Helsinki, approved by the responsible medical ethical committee, CMO Arnhem Nijmegen.

\section{Consent for publication}

Not applicable.

\section{Competing interests}

The authors declare that they have no competing interests.

\section{Author details}

'Department of Rheumatology, Sint Maartenskliniek, Hengstdal nr. 3, 6574 NA Ubbergen, The Netherlands. ${ }^{2}$ Department of Rheumatology, Radboud University Nijmegen Medical Centre, Geert Grooteplein 8, 6500 HB Nijmegen, The Netherlands. ${ }^{3}$ Department of Internal Medicine, Radboud University Nijmegen Medical Centre, Geert Grooteplein 8, 6500 HB Nijmegen, The Netherlands.

\section{Received: 24 April 2020 Accepted: 7 December 2020}

Published online: 04 January 2021

\section{References}

1. Avina-Zubieta JA, Thomas J, Sadatsafavi M, Lehman AJ, Lacaille D. Risk of incident cardiovascular events in patients with rheumatoid arthritis: a metaanalysis of observational studies. Ann Rheum Dis. 2012;71(9):1524-9.

2. Bartoloni E, Shoenfeld Y, Gerli R. Inflammatory and autoimmune mechanisms in the induction of atherosclerotic damage in systemic rheumatic diseases: two faces of the same coin. Arthritis Care Res (Hoboken). 2011;63(2):178-83.

3. Arts EE, Popa C, Den Broeder AA, Semb AG, Toms T, Kitas GD, et al. Performance of four current risk algorithms in predicting cardiovascular events in patients with early rheumatoid arthritis. Ann Rheum Dis. 2015; 74(4):668-74.

4. Fransen J, Kazemi-Bajestani SM, Bredie SJ, Popa CD. Rheumatoid arthritis disadvantages younger patients for cardiovascular diseases: a meta-analysis. Plos One. 2016;11(6):e0157360.

5. Arts E, Fransen J, Lemmers $H$, Stalenhoef $A$, Joosten L, van Riel $P$, et al. High-density lipoprotein cholesterol subfractions HDL2 and HDL3 are reduced in women with rheumatoid arthritis and may augment the cardiovascular risk of women with RA: a cross-sectional study. Arthritis Res Ther. 2012;14(3):R116.

6. Bove R. Autoimmune diseases and reproductive aging. Clin Immunol. 2013; 149(2):251-64.

7. Pfeifer EC, Crowson CS, Amin S, Gabriel SE, Matteson EL. The influence of early menopause on cardiovascular risk in women with rheumatoid arthritis. J Rheumatol. 2014;41(7):1270-5.

8. Pikwer M, Bergstrom U, Nilsson JA, Jacobsson L, Turesson C. Early menopause is an independent predictor of rheumatoid arthritis. Ann Rheum Dis. 2012;71(3):378-81.

9. Peters MJ, Symmons DP, McCarey D, Dijkmans BA, Nicola P, Kvien TK, et al. EULAR evidence-based recommendations for cardiovascular risk management in patients with rheumatoid arthritis and other forms of inflammatory arthritis. Ann Rheum Dis. 2010;69(2):325-31.

10. Statistics Netherlands.Centre for Policy Related Statistics. http://www.cbs.nl/.

11. Arts EE, Popa CD, Den Broeder AA, Donders R, Sandoo A, Toms T, et al. Prediction of cardiovascular risk in rheumatoid arthritis: performance of original and adapted SCORE algorithms. Ann Rheum Dis. 2016;75(4):674-80.

12. Crowson CS, Gabriel SE, Semb AG, van Riel P, Karpouzas G, Dessein PH, et al. Rheumatoid arthritis-specific cardiovascular risk scores are not superior to general risk scores: a validation analysis of patients from seven countries. Rheumatology (Oxford). 2017;56(7):1102-10.

13. Crowson CS, Rollefstad S, Kitas GD, van Riel PL, Gabriel SE, Semb AG, A Trans-Atlantic Cardiovascular Risk Consortium for Rheumatoid Arthritis (ATACC-RA). Challenges of developing a cardiovascular risk calculator for patients with rheumatoid arthritis. Plos One. 2017;12(3):e0174656.

14. Solomon DH, Greenberg J, Curtis JR, Liu M, Farkouh ME, Tsao P, et al. Derivation ans internal validation of expanded cardiovascular risk prediction score for rheumatoid arthritis: a Consortium of Rheumatology Researchers of North America Registry Study. Arthritis Rheumatol. 2015;67(8):1995-2003.

15. Chae CU, Derby CA. The menopausal transition and cardiovascular risk. Obstet Gynecol Clin N Am. 2011;38(3):477-88.

16. Hu FB, Stampfer MJ, Solomon CG, Liu S, Willett WC, Speizer FE, et al. The impact of diabetes mellitus on mortality from all causes and coronary heart disease in women: 20 years of follow-up. Arch Intern Med. 2001;161(14): 1717-23.

17. Corrales A, Gonzalez-Juanatey C, Peiro ME, Blanco R, Llorca J, Gonzalez-Gay MA. Carotid ultrasound is useful for the cardiovascular risk stratification of patients with rheumatoid arthritis: results of a population-based study. Ann Rheum Dis. 2014;73(4):722-7.

18. Kawai VK, Chung CP, Solus JF, Oeser A, Raggi P, Stein CM. The ability of the 2013 American College of Cardiology/American Heart Association cardiovascular risk score to identify rheumatoid arthritis patients with high coronary artery calcification scores. Arthritis Rheumatol. 2015;67(2):381-5.

19. Corrales A, Dessein PH, Tsang L, Pina T, Blanco R, Gonzalez-Juanatey C, et al. Carotid artery plaque in women with rheumatoid arthritis and low estimated cardiovascular disease risk: a cross-sectional study. Arthritis Res Ther. 2015:17:55

20. Corrales A, Parra JA, Gonzalez-Juanatey C, Rueda-Gotor J, Blanco R, Llorca J, et al. Cardiovascular risk stratification in rheumatic diseases: carotid ultrasound is more sensitive than Coronary Artery Calcification Score to detect subclinical atherosclerosis in patients with rheumatoid arthritis. Ann Rheum Dis. 2013;72(11):1764-70

21. Van Doornum S, McColl G, Wicks IP. Accelerated atherosclerosis: an extraarticular feature of rheumatoid arthritis? Arthritis Rheum. 2002:46(4): 862-73

22. Park YB, Lee SK, Lee WK, Suh CH, Lee CW, Lee $\mathrm{CH}$, et al. Lipid profiles in untreated patients with rheumatoid arthritis. J Rheumatol. 1999;26(8):1701-4.

23. Ross R. Atherosclerosis--an inflammatory disease. N Engl J Med. 1999;340(2): 115-26.

24. Nissen SE, Yeomans ND, Solomon DH, Luscher TF, Libby P, Husni ME, et al. Cardiovascular safety of celecoxib, naproxen, or ibuprofen for arthritis. N Engl J Med. 2016;375(26):2519-29.

\section{Publisher's Note}

Springer Nature remains neutral with regard to jurisdictional claims in published maps and institutional affiliations. 